\title{
CurraNZ blackcurrant improves cycling performance and recovery in trained endurance athletes
}

\author{
Mark ET Willems*, Stephen D Myers, Sam D Blacker, Matthew D Cook \\ From The Eleventh International Society of Sports Nutrition (ISSN) Conference and Expo \\ Clearwater Beach, FL, USA. 20-21 June 2014
}

\section{Background}

Peripheral blood flow is increased by blackcurrant intake in humans [1], potentially by anthocyanin-induced vasorelaxation and vasodilation [2], which may affect substrate delivery, exercise performance and recovery. We examined the effect of 1-week CurraNZ blackcurrant on substrate oxidation during steady state cycling, $16.1 \mathrm{~km}(10 \mathrm{mile})$ time-trial performance and lactate clearance following exercise in trained endurance athletes.

\section{Methods}

Nine male endurance athletes (club level cyclists and triathletes with $>3$ yrs experience; age: $35 \pm 14$ years, height: $179 \pm 3 \mathrm{~cm}$, body mass: $76 \pm 9 \mathrm{~kg}$, BMI: $24 \pm 2$, VO2max: 54 $\pm 6 \mathrm{~mL} \mathrm{~kg}-1 \mathrm{~min}-1$, maximum power: $366 \pm 42 \mathrm{~W}$, mean $\pm \mathrm{SD}$ ) volunteered to visit the laboratory for 4 sessions. Cycling tests for lactate responses (4 min stages with 2 min recovery, start power $50 \mathrm{~W}$ with $30 \mathrm{~W}$ increments) and maximum oxygen uptake (start power $50 \mathrm{~W}$ for 4 min with $30 \mathrm{~W}$ min-1 increments) at self-selected pedal cadence (SRM ergometer, SRM International, Germany) were performed to establish power values at $45 \%, 55 \%$, and $65 \%$ of VO2max. Experimental design was doubleblind and randomized with a wash-out period of 2 weeks. Familiarized participants were tested following 7 days of blackcurrant extract (CurraNZ, 300mg/day) (Health Currancy Ltd, UK) or placebo (P) capsule intake. Indirect calorimetry (Douglas bag technique) was used at low $(\sim 45 \%)$ and moderate intensity ( $55 \%$ and $\sim 65 \%)$ steadystate cycling (10 min stages) with lactate sampling. Subsequently, a $16.1 \mathrm{~km}$ time-trial was performed with lactate

\footnotetext{
* Correspondence: M.Willems@chi.ac.uk

University of Chichester, Chichester, United Kingdom
}

sampling during recovery for $20 \mathrm{~min}$. Paired t-tests were used for analysis with significance accepted at $\mathrm{p}<.05$. Consent to publish the results was obtained from all participants.

\section{Results}

There were no differences between CurraNZ and placebo at $\sim 45 \%, \sim 55 \%$ and $\sim 65 \% \mathrm{VO} 2 \mathrm{max}$ for fat oxidation, carbohydrate oxidation, lactate, heart rate, minute ventilation and cycling economy $(\mathrm{P}>.05)$. CurraNZ improved $16.1 \mathrm{~km}$ time-trial performance substantially by $3.6 \%$ (P: $1784 \pm 121$, CurraNZ: $1718 \pm 108$ sec, $\mathrm{p}=.03,7$ out of 9 participants improved, range -2.2-8.6\%). Lactate was higher with CurraNZ immediately following the time-trial (P: $5.4 \pm 1.6$, CurraNZ: $6.5 \pm 1.8 \mathrm{mmol} \mathrm{L}-1, \mathrm{p}=.03$, all participants). Lactate decreases were higher with CurraNZ after 20 min of passive recovery following the time-trial ( $P: 3.2 \pm 0.8$, CurraNZ: $3.9 \pm 1.2 \mathrm{mmol} \mathrm{L-1,} \mathrm{p}=.03,8$ out of 9 participants).

\section{Conclusions}

Intake of CurraNZ blackcurrant is associated with 1) normal metabolic and physiological responses at low and moderate intensity cycling, 2) improved $16.1 \mathrm{~km} \mathrm{(10}$ mile) time-trial cycling performance, 3) potentially a higher lactate tolerance during time-trial performance, and 4) increased lactate clearance after exercise indicating improved recovery. It is concluded that CurraNZ blackcurrant intake has favourable implications in endurance athletes for aerobic exercise performance, lactate tolerance, and recovery.

\section{Acknowledgement}

Funding for this study and conference attendance was provided by Health Currancy Ltd (UK). 
Published: 1 December 2014

\section{References}

1. Matsumoto H, Kamm KE, Stull JT, Azuma H: Delphinidin-3-rutinoside relaxes the bovine ciliary smooth muscle through activation of ETB receptor and NO/cGMP pathway. Exp Eye Res 2005, 80(3):313-22.

2. Ziberna L, Kim JH, Auger C, Passamonti S, Schini-Kerth V: Role of endothelial cell membrane transport in red wine polyphenols-induced coronary vasorelaxation: involvement of bilitranslocase. Food Funct 2013, $4(10): 1452-6$.

doi:10.1186/1550-2783-11-S1-P14

Cite this article as: Willems et al: CurraNZ blackcurrant improves cycling performance and recovery in trained endurance athletes. Journal of the International Society of Sports Nutrition 2014 11(Suppl 1):P14.

Submit your next manuscript to BioMed Central and take full advantage of:

- Convenient online submission

- Thorough peer review

- No space constraints or color figure charges

- Immediate publication on acceptance

- Inclusion in PubMed, CAS, Scopus and Google Scholar

- Research which is freely available for redistribution

Submit your manuscript at www.biomedcentral.com/submit 